January 2011

\title{
Implementing routine provider-initiated HIV testing in public health care facilities in Kenya: a qualitative descriptive study of nurses' experiences
}

Catrin Evans

University of Nottingham

Eunice Ndirangu

Aga Khan University, eunice.ndirangu@aku.edu

Follow this and additional works at: http://ecommons.aku.edu/eastafrica_fhs_sonam

Part of the Nursing Commons, and the Physiotherapy Commons

\section{Recommended Citation}

Evans, C., Ndirangu, E. (2011). Implementing routine provider-initiated HIV testing in public health care facilities in Kenya: a qualitative descriptive study of nurses' experiences. AIDS Care, 23(10), 1291-1297.

Available at: $\mathrm{http}: / /$ ecommons.aku.edu/eastafrica_fhs_sonam/42 


\section{Implementing Routine Provider Initiated HIV Testing in Public Healthcare Facilities in Kenya: A Qualitative Descriptive Study of Nurses' Experiences}

\section{Abstract}

Routine 'provider-initiated testing and counselling' (PITC) for HIV has been implemented amidst concern over how consent, confidentiality and counselling (the $3 C^{\prime}$ 's) can be maintained in underresourced health care settings. In Kenya, PITC has been rolled out since 2005, HIV prevalence is $7.1 \%$ and over $86 \%$ of adults have not been tested. Kenyan nurses are the main cadre implementing PITC but little is known about their experiences of incorporating HIV testing into everyday practice and the challenges faced in maintaining the $3^{\prime} \mathrm{Cs}$ within their work environments. This study aimed to explore these issues and adopted a qualitative multi-method design using a convenience sampling approach. Two focus group discussions (total $n=12$ ) and 13 in-depth individual interviews were undertaken with nurses from 11 different public health care facilities in Nairobi and its surrounding areas (including in- and out-patient settings). Data were analysed thematically. Nurses identified a range of personal, client and health system challenges in the everyday application of PITC. These included: (i) the contradictions of normalising a highly stigmatised disease and the difficulty of providing client centred care within a routinised and target oriented work culture; (ii) the challenge of dealing with ethically complex client situations in which the principles of the $3 C^{\prime}$ 's could be difficult to uphold; and, (iii) lack of time, resources, space and recognition within workplace environments (especially in-patient settings) that, likewise, led to problems with maintaining the $3 C^{\prime}$ s. In-patient nurses in particular identified problems associated with testing in a multi-disciplinary context, suggesting that other health professionals appeared to routinely flout the PITC guidelines. In conclusion, this study shows that the process of translating policy into practice is invariably complex and that more research is needed to explore PITC practices, particularly in in-patient settings. Nurses require supervision and support to negotiate the challenges and to fulfil their roles effectively.

\section{Keywords}

HIV; provider initiated testing; nurses, Kenya

\section{Introduction}


Provider initiated HIV testing and counselling (PITC) is a key strategy in the global effort to increase HIV testing rates. Global PITC guidelines propose that all clients attending health services in high prevalence areas be offered an HIV test, regardless of their presenting complaint (WHO/UNAIDS, 2007). PITC has significant implications for health care teams, requiring increased levels of engagement with HIV issues, higher work loads and/or the need to re-organise working patterns to incorporate HIV testing into routine care. In response to concerns about the protection of individual rights in resource limited clinical settings (Gruskin, Ahmed, \& Ferguson, 2008; Rennie \& Behets, 2006), WHO/UNAIDS (2007) guidelines state that PITC should only be implemented in contexts where a minimum package of HIV care and the $3 C^{\prime}$ s - informed (verbal) consent, confidentiality and counselling can be guaranteed (WHO/UNAIDS, 2007 p.30).

\section{Kenyan Context}

This paper examines PITC in Kenya where HIV prevalence is $7.1 \%$; over $86 \%$ of the adult population has not had an HIV test and approximately $83 \%$ of people who are HIV positive are unaware of their diagnosis (Ministry of Health, 2008a). PITC has been progressively rolled out in Kenyan public sector health facilities (which comprise approximately 51\% of health services) since 2005 (Marum, Taegtmeyer, \& Chebet, 2006; Ministry of Health, 2009). PITC scale up is supported by national guidelines (Ministry of Health, 2008b) and a national health worker training programme. In public sector health facilities, PITC is usually carried out using rapid tests and is primarily undertaken by nurses.

\section{Literature Review}

Research from across sub-Saharan Africa shows high levels of patient acceptance of PITC when measured quantitatively (Obermeyer \& Osborn, 2007; Wanyenze et al., 2008). However, in Kenya (as elsewhere), considerable variation in testing uptake and return for follow up between different testing sites has been reported, indicating that specific site factors have an impact on the patient experience (Anand et al., 2009). A number of qualitative studies highlight that patients can feel pressured into testing, are mistrustful of healthcare staff or report poor quality care (Delva, Mutunga, Quaghebeur, \& Temmerman, 2006; Groves, Maman, Msomi, Makhanya, \& Moodley, 2010; Hamilton et al., 2008; Painter et al., 2004). 
In Kenya, a 2005 national health worker survey found high levels of knowledge and support for the PITC programme (National AIDS and STD Control Programme, 2006). However, a recent evaluation of the PITC national training programme found that only $30 \%$ of health facilities were fully implementing PITC citing staff shortages, lack of space and low staff morale as associated factors (Kathambana et al., 2008). Similar findings have been reported in a range of other countries (Evans \& Ndirangu, 2009; Minnie, van der Walt, \& Klopper, 2009).

To date, HIV testing research has focused upon out-patient settings (primarily antenatal or TB clinics). Very little is known about PITC practice within in-patient contexts.

\section{Research Aim}

Given the critical role of nurses in ensuring high quality PITC implementation in Kenya, this paper reports on an exploratory study that aimed: (i) to investigate key challenges in PITC from a nursing perspective and, (ii) to explore ways in which the principle of the $3 C^{\prime}$ 's (consent, confidentiality and counselling) were being managed in every day practice.

\section{Methods}

The study adopted an interpretative qualitative methodology (Rubin \& Rubin, 1995). A multi-method design was used, involving 2 focus groups ( $n=6$ in each) and 13 semi-structured interviews (Green \& Thorogood, 2004). The focus groups were conducted to explore social/professional norms and discourses around HIV testing and of nurses' role in HIV care. These were followed by individual interviews to elicit accounts of actual HIV testing practices and experiences in particular workplace contexts (Barbour, 1998).

Data were collected by the second author, a Kenyan nurse-researcher. The sampling strategy was deliberately broad in order to represent nurses from a range of workplaces. The inclusion criteria were that participants had a nursing qualification, worked in a public health sector facility in or around Nairobi and that they either delivered PITC directly or worked in a setting where PITC directly impacted upon their everyday nursing practice (e.g. having to care for in-patients who had just received a HIV diagnosis). There were a total of 25 nurse-participants, representing 11 different healthcare facilities; 13 worked in in-patient settings and 12 worked in out-patient settings and/or held managerial positions - see tables 1 and 2 for further details. 
Recruitment for the individual interviews used convenience sampling; the second author contacted health facilities (Hospitals A-D and Health Centre A) where she had contacts amongst senior nursing staff who, in turn, facilitated access to potential participants. The focus group participants likewise comprised a convenience sample in that they were drawn from a larger group of nurses who were attending a course (not connected to HIV) in a Nairobi School of Nursing. The interviews (lasting 45 60 minutes) were held in a quiet room in the individual's workplace. The focus group discussions were held in the School of Nursing.

Ethical permission to conduct the study was obtained from the Aga Khan University Research Ethics Committee, the Kenyan Ministry of Education Science and Technology and individual hospital ethics committees. All participants provided written informed consent.

\section{Data Analysis}

All interviews/group discussions were digitally recorded, transcribed and checked for accuracy. Data were analysed manually using inductive thematic content analysis (Boyatzis, 1998), paying particular attention to atypical cases and to contextual variations (Tobin \& Begley, 2004). Initially, the interviews and focus groups were analysed separately but strikingly similar themes emerged from both data sets, so they were combined. To enhance rigour, transcripts were read by both authors and a common coding scheme and thematic framework was agreed. Three major categories were identified.

\section{Findings}

(1) The Contradictions of Routinisation

All the nurse participants were highly knowledgeable about the PITC policy and supported its rationale. However, nurses identified two contradictions that PITC posed for their everyday practice. The first was associated with trying to normalise a highly stigmatised disease. On the one hand, many nurses noted that the routine offer of a test made HIV seem "just like any other chronic disease", and that, in practice, routinisation made it easier for both staff and patients to talk about HIV. So, whereas previously, 'HIV-talk' had been conducted using coded forms of communication (e.g. oblique references by health-workers to " $P$-24 antigen") or by complicated guess work based 
on indirect hints from patients (e.g. references to "weight loss"), nurses felt that routinisation now facilitated more open conversations:

Before, a patient will come - inside his heart wanting to do the test - but just asking you would be a problem for him, but now its all in the open (N13)

On the other hand, nurses recognised that in the public mind HIV was not yet a 'routine' illness due to the stigma that surrounded it. Indeed, many participants commented that some nurses themselves still stigmatised HIV and could exhibit a damaging judgementalism:

We talk as if it's a bad thing; we also discuss these patients despite saying that we are going to keep the confidentiality - so of course patients will not want to test (FGD1, P5)

The second contradiction was associated with trying to maintain a client centred philosophy of care within a routinised and target driven practice context. For example, many nurses were not convinced about the PITC guideline to minimise pre-test discussions in order to expedite client through-put. Their own experience was that in many cases (because of HIV-related stigma), patients did require in-depth pre-test discussions to help them to overcome their fears and to give consent:

Pre-test counselling is the most important thing because it prepares the patient to receive a positive result - if you just test - where do you start when the patient turns out to be positive? (FGD2, P3)

In such cases, nurses' narratives indicated that, where possible, they adapted the guidelines, tailoring their discussions to an in-depth understanding of the patients' situation:

With this patient, I knew I had to take longer. So I took her very slowly through everything. She didn't want to test, but then, after some persuasion, she decided to let me go ahead (N12)

Many of the participants (particularly from out-patient settings) felt that routine testing had created a target- rather than client-centred approach to HIV care and that this inevitably compromised quality of care: 
If you see the crowds at the clinic they [the supervisors] will be very happy......but they will not bother to find out the quality of work you did with each client.... They are pressurizing the staff...... if you do not test this many numbers then you are a failure and we are wondering where this 50 will come from. If we coerce these patients to be tested - then they won't come back. It won't be provider-initiated, it will be provider-coercion (FGD2, P1)

(2) Everyday Ethics

The data indicated that PITC sometimes created acute ethical dilemmas within nurses' everyday practice which were experienced as very stressful.

A commonly cited situation was where patients refused to have the HIV test. In dealing with such cases, nurses repeatedly returned to the principle of "do no harm" to justify their decision making. So, for example, nurses noted that they would usually give the patient more time or simply have to accept the patient's choice (even if they did not agree with it). However, a number of nurses described situations where they had applied strong pressure to persuade patients to take the test. In principle, this runs counter to the PITC guidelines to elicit voluntary informed consent. In the examples given however, nurses clearly felt that not testing would have caused even greater harm:

Sometimes you find a patient where you know the spouse or a child has died because of AIDS and they refuse to be tested despite the counselling and all that. It is challenging because upon discharge you will lose that patient. So you find you might be aggressive for the sake of helping them, not because you want to create harm, but just because you want them to benefit, even though you have to use a cold and aggressive way of handling such a situation..............Like there was a girl on the ward and I told her-either you lose your life or comply with the protocols of the hospital. then, you see. .it was like forcing......but at the end of it she accepted. But it was for her benefit (N2)

None of the participants mentioned the multi-disciplinary team as a source of advice in dealing with such situations. In fact, several interviewees (all from in-patient settings) described incidents where medical doctors or clinical officers had tested patients without consent, indicating that this was common practice:

It happens many times when the doctors are doing their rounds. Many are the times they don't inform the patients what is wrong with them. The doctor notes down the test and the 
next thing you know, the clinical officer is poking into this patient drawing blood and the patient doesn't know why. The patients are so innocent, they trust that whatever you are doing is for his own good........they do not demand to know (N6)

Interestingly, all such narratives were recounted without comment or judgement. When the nurses were asked if they ever questioned the practice of a doctor, they indicated that their views would be dismissed:

Sometimes we do suggest about patient management with the doctor but then the doctors feel you are undermining them - you know - you are just a nurse (N5)

Another difficult situation was when HIV positive clients refused to disclose their status to others who were potentially at risk. Again, in most cases, nurses spoke of having to accept and respect a patient's choice. Nonetheless, in four interviews, nurses admitted to breaching confidentiality. In all four cases, the situation involved a male patient refusing to inform a spouse and was rationalised in terms of acting in the public good:

You know, this whole issue is gender biased because the men, they keep it to themselves and the women perish. That part of the confidentiality - I think it's killing us. It should be mandatory that the spouse news is told to the other spouse. It is not opening up other people's issues, but it is just taking care of the others (FGD1, P4)

Nurses described a deep discomfort in dealing with a related scenario in which the family was anxious, was bearing a high financial and physical burden of care, and yet the patient would not disclose. Some nurses felt it was ethically wrong to keep such relatives in the dark:

See, the relative is the one paying the bill and they are asking all the time 'what has the doctor said'?... As a nurse you are fixed because on the one hand there is confidentiality and on the other there is the relatives' vulnerability..... Mostly it is women, and you see that they will not be able to take care, so you just go ahead and give information to that person (N10)

Nurses also described becoming de-moralised at the sheer number of patients who tested positive and at their sense of powerlessness to help those in need: 
You test them and then they tell you their history and you just don't know what to do next. They are poor and they can't afford food, and then you ask yourself 'what can I do to help this person'. It really affects me (N10)

Working with HIV therefore exacted an emotional toll. In some institutions, specialist HIV counsellors received monthly clinical supervision, however, this was not available everywhere and did not include general clinic/ward nurses.

\section{(3) Workplace Environment and Support}

A major source of stress and frustration for the participants related to their working environments. Lack of staff, lack of resources and lack of time were the most common complaints leading to patients being kept waiting, being sent away un-tested or being dealt with abruptly.

Sometimes you find like in my ward you are alone.....you have all the clients for testing - so what we do is sketchy - you know - shallow, not deep (N11)

Many nurses identified the over-crowded ward environment (where beds are shared or positioned close together, where there are no screens and where relatives may be present at all times) as a challenge to maintaining dignity and confidentiality:

We don't have cubicles....so it forces us to go bed by bed as we give a report....patients have come to realise the language we use and then you say "this immuno-suppressed patient or this is a p24 patient" and it just gives away the whole story to the others (N13)

In addition, nurses described how the need to involve relatives in patients' care also led to inadvertent breaches in confidentiality:

Like, when we remove the blood then it is taken to another facility for testing.....then....in most cases it is the relatives who bring the results back and some of the relatives know about the CD4 count and why it is done, so we actually breach confidentiality (FGD1, P5) 
Many participants expressed the view that the additional burden created by PITC had been insufficiently recognised in their workplaces, leading to de-motivation and a task-oriented mentality:

When it comes to doing PITC, if you are trained and the other nurse counsellor is not there, you are not much willing to do it - there is no recognition for it, so you just wait until she comes back (N8)

Indeed, a general perception that nurses were under-valued at the wider policy level was strongly expressed in the focus group discussions:

If you look at all the programme implementation - anything on HIV - it ends up with the nurse. If the nurse does not implement it, the whole programme falls back. But if you look at the people who are being rewarded for that particular programme, the nurse is at the back. So there is a lot of de-motivation. People are creating policy up there, they are not coming down (FG1, P2).

\section{Discussion}

Although small scale, our study findings are highly are consistent with related research in this area (Mavhandu-Mudzusi, Netshandama, \& Dhavhana-Maselesele, 2007; Mkhabela, Mavundla, \& Sukati, 2008; Nuwagaba-Biribonwoha, Mayon-White, Okong, \& Carpenter, 2007) and show that nurses face a number of challenges in implementing PITC.

The first relates to the routinisation of a stigmatised disease. The nurse participants agreed that PITC confronted HIV stigma and enabled a greater openness about the disease, but recognised that its implementation was hindered by existing stigmatised social norms around HIV (expressed by nurses as well as by patients). Nurses faced a contradiction in that addressing stigma required an individualised approach to patient care - but this was difficult to deliver because of routinised testing protocols with minimal pre-test discussion, a focus on meeting targets and lack of time and/or staff. Similar findings have been reported by Pope et al (2010) and Rohleder \& Schwartz (2005).

Second, the study indicates that PITC can be stressful - relating in part to the emotional labour of managing complex client situations, and, in part, to workplace resources and conditions. This study 
identified a number of areas where maintenance of the $3 C^{\prime}$ s was problematic for nurses, including several examples where clients had been pressured to consent and where confidentiality had been breached. Nurses expressed ambivalence about PITC's focus on protection of individual rights in the face of safeguarding the public health and in a cultural context where women lack power and where health decision making is based on collective rather than purely individual interests (cf. Mulemi, 2008). A recent study in Malawi, Angotti (2010) showed that, like the nurses in this sample, HIV counsellors learned to use their discretion to creatively manage difficult ethical situations. One way of addressing these dilemmas of everyday practice would be for nurses to receive greater opportunities for clinical supervision and group support in which they could formulate their own workplace-specific strategies for practice development. Any interventions to support PITC need to pay heed to the sense of disempowerment expressed by nurses in this study however, and should consider how to support nurses to secure a greater sense of autonomy and recognition in the workplace.

Finally, this study also identified particular challenges to maintaining the $3 C^{\prime}$ 's within in-patient settings. Although quantitative studies on PITC uptake have been published from in-patient care (e.g. Gichangi et al., 2006; Wanyenze et al., 2008), to our knowledge, there have been no in-depth qualitative studies examining the process of PITC implementation in hospital wards. There is an urgent need for more research on HIV testing practice within the in-patient context, and our findings suggests that such research must also include the practices of doctors and clinical officers.

\section{Conclusion}

Despite a strong national training programme and clear guidelines, the process of translating PITC policy into practice is invariably complex, shaped by client, provider and health system factors, and, as this study shows, by specific local interpretations of key ethical principles. Further understanding of the complexities of PITC implementation in different cultural contexts is hindered by the fact that most studies (including this one) have relied on self-reported recall of PITC experiences. We suggest that future research should include observation of actual HIV testing practice and a strong focus on the patient experience.

In conclusion, nurses are on the front lines of PITC implementation in Kenya and require continued support to negotiate the challenges and to fulfil their roles effectively. 


\section{Acknowledgements}

We are grateful for the support of a Boehringer Ingelheim Research Grant administered through the UK National HIV Nurses Association. We thank all the nurses who kindly agreed to participate in this study.

\section{References}

Anand, A., Shiraishi, R., Sheikh, A., Marum, L., Bolu, O., Mutsotso, W., et al. (2009). Site factors may be more important than participant factors in explaining HIV test acceptance in the prevention of mother to child HIV transmission programme in Kenya, 2005. Tropical Medicine and International Health, 14(10), 1215-1219.

Angotti, N. (2010). Working outside the box: how HIV counselors in sub-Saharan Africa adapt western HIV testing norms. Social Science and Medicine, 71, 986-993.

Barbour, R. (1998). Mixing qualitative methods: quality assurance or qualitative quagmire? Qualitative Health Research, 8, 352-361.

Boyatzis, R. (1998). Transforming qualitative data: thematic analysis and code development. London: Sage.

Delva, W., Mutunga, L., Quaghebeur, A., \& Temmerman, M. (2006). Quality and Quantity of Antenatal HIV Counselling in a PMTCT Programme in Mombasa, Kenya. AIDS Care, 18(3), 189-193.

Gichangi, P., Estambale, B., Bwayo, J., Rogo, K., Ojwang, S., Njugunas, E., et al. (2006). The Acceptability of HIV Testing in Patients with Invasive Cervical Cancer in Kenya International Journal of Gynaecological Cancer, 16, 681-685.

Green, J., \& Thorogood, N. (2004). Qualitative Methods for Health Research. London: Sage.

Groves, A., Maman, S., Msomi, S., Makhanya, N., \& Moodley, D. (2010). The complexity of consent: women's experiences of testing for HIV at an antenatal clinic in Durban, South Africa. AIDS Care.

Gruskin, S., Ahmed, S., \& Ferguson, L. (2008). Provider-initiated HIV testing and counselling in health facilities: What does this mean for the health and human rights of pregnant women? Developing World Bioethics, 8(1), 23-32.

Hamilton, C., Okoko, D., Tolhurst, R., Kilonzo, N., Theobald, S., \& Taegtmeyer, M. (2008). Potential for abuse in the VCT counselling room: service provider's perceptions in Kenya. Health Policy and Planning, 23(6), 390-396.

Kathambana, F., Koskei, N., Lynam, P., Cherutich, P., Chembeni, J., \& Malonza, I. (2008). Challenges of scaling up provider initiated testing and counselling in Kenya: Paper presented at XVII International AIDS Conference, Mexico, August 3-8.

Marum, E., Taegtmeyer, M., \& Chebet, K. (2006). Scale Up of Voluntary HIV Counselling and Testing in Kenya. Journal of the American Medical Association 296(7), 859-862.

Mavhandu-Mudzusi, A., Netshandama, V., \& Dhavhana-Maselesele, M. (2007). Nurse's experiences of delivering voluntary counselling and testing services for people living with HIV/AIDS in the Vhembe district, Limpopo province, South Africa. Nursing and Health Sciences, 9, 254-262.

Ministry of Health. (2008a). Kenya AIDS Indicator Survey (KAIS) 2007. Nairobi: Ministry of Health 
Ministry of Health. (2008b). National guidelines for HIV testing and counselling in Kenya. Nairobi, Kenyan National AIDS and STD Control Programme.

Ministry of Health. (2009). Kenya AIDS National Strategic Plan, 2009-10 to 2010-13: delivering universal access to services. National AIDS Control Council.

Mkhabela, M., Mavundla, T., \& Sukati, N. (2008). Experiences of nurses working in voluntary counselling and testing services in Swaziland. Journal of the Association of Nurses in AIDS Care, 19, 470-479.

Mulemi, B. (2008). Patients' perspectives on hospitalisation: experiences from a cancer ward in Kenya. Anthropology and Medicine, 15(2), 117-131.

National AIDS and STD Control Programme. (2006). Preparedness for HIV/AIDS service delivery: the 2005 Kenya health workers' survey. NASCOP, Ministry of Health, Nairobi.

Nuwagaba-Biribonwoha, H., Mayon-White, R., Okong, P., \& Carpenter, L. (2007). Challenges Faced by Health Workers in Implementing the Prevention of Mother to Child HIV Transmission (PMTCT) Programme in Uganda. Journal of Public Health, 29(3), 269-274.

Obermeyer, C., \& Osborn, M. (2007). The utilisation of testing and counselling for HIV: A review of the social and behavioural evidence. American Journal of Public Health, 97, 1762-1774.

Painter, T., Diaby, K., Matia, D., Lin, L., Sibailly, T., Kouassi, M., et al. (2004). Women's reasons for not participating in follow up visits before starting short course antiretroviral prophylaxis for prevention of mother to child transmission of HIV: a qualitative interview study. British Medical Journal, 329, 543-546.

Pope, D., Atkins, S., DeLuca, A., Hausler, H., Hoosain, E., Celentano, D., et al. (2010). South African TB nurses' experiences of provider-initiated HIV counseling and tesing in the Eastern Cape Province: a qualitative study. AIDS Care, 22(2), 238-245.

Rennie, S., \& Behets, F. (2006). Desperately Seeking Targets: The Ethics of Routine HIV Testing in Low Income Countries. Bulletin of the World Health Organisation, 84(1), 1-11.

Rohleder, P., \& Schwartz, L. (2005). "What I've noticed is that they need the stats": Lay HIV counsellor's reports of working in a task-oriented health care system. AIDS Care, 17(3), 397-406.

Rubin, H., \& Rubin, I. (1995). Qualitative Interviewing: The Art of Hearing Data. Thousand Oaks, California: Sage.

Tobin, G., \& Begley, C. (2004). Methodological rigour within a qualitative framework. Journal of Advanced Nursing, 48(4), 388-396.

Wanyenze, R., Nawavvu, C., Namale, A., Mayanja, B., Bunnell, R., Abang, B., et al. (2008).

Acceptability of routine HIV counselling and testing, and HIV seroprevalence in Ugandan hospitals.

Bulletin of the World Health Organisation, 86, 302-309.

WHO/UNAIDS. (2007). Guidance on Provider-Initiated HIV Testing and Counselling in Health Facilities. Geneva: World Health Organisation. 
Table 1: Sample Characteristics - Clinical Sites and Nursing Roles

\begin{tabular}{|c|c|c|c|}
\hline $\begin{array}{l}\text { Clinical Sites } \\
\mathrm{n=11} \text {, labelled A-K }\end{array}$ & $\begin{array}{c}\text { Interviews } \\
\mathrm{n}=13\end{array}$ & $\begin{array}{l}\text { Focus Groups } \\
n=12\end{array}$ & $\begin{array}{l}\text { Total } \\
\mathbf{n}=\mathbf{2 5}\end{array}$ \\
\hline $\begin{array}{l}\text { Government hospitals in Nairobi } \\
(A, B)\end{array}$ & - $\quad$ Hospital 'A' (all in-patient ward nurses) & $\begin{array}{ll}\mathbf{n = 4} & \\
\text { - Hospital 'A' (1 deputy in-charge, } 1 \text { ward nurse) } \\
\text { - Hospital ' } B \text { ', (1 nursing officer in charge, } 1 \\
\\
\text { ward nurse) }\end{array}$ & $40 \%$ \\
\hline $\begin{array}{l}\text { Government district hospitals outside } \\
\text { Nairobi } \\
\text { (C, D, E, F) }\end{array}$ & $\begin{array}{rr}\mathbf{n = 2} & \\
- & \text { Hospital ' } \mathrm{E} \text { ' (1 ward nurse) } \\
& - \text { Hospital 'C' (1 ward nurse) }\end{array}$ & $\begin{array}{ll}\mathbf{n = 5} & \\
\text { - } & \text { Hospital 'E' (1 ward nurse) } \\
\text { - } & \text { Hospital 'C' (1 ward nurse) } \\
\text { - } & \text { Hospital 'F' (1 ward nurse, } 1 \text { antenatal clinic } \\
& \text { nurse) } \\
\text { - } & \begin{array}{l}\text { Hospital 'D' (1 HIV comprehensive care centre } \\
\text { nurse) }\end{array}\end{array}$ & $28 \%$ \\
\hline $\begin{array}{l}\text { Government provincial hospital } \\
(\mathrm{G}, \mathrm{H})\end{array}$ & $\begin{array}{ll}\mathbf{n = 1} & \\
\text { - Hospital 'G' (1 HIV comprehensive care } \\
\text { centre nurse) }\end{array}$ & n=1 $\quad$ Hospital ' $\mathrm{H}^{\prime}$ ' (1 nurse in charge) & $8 \%$ \\
\hline $\begin{array}{l}\text { Government health centre } \\
(\mathrm{I}, \mathrm{J}, \mathrm{K})\end{array}$ & 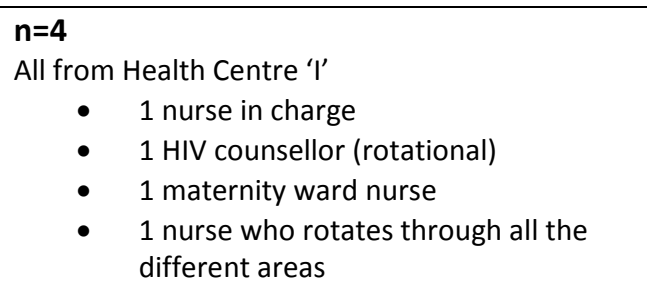 & $\begin{array}{ll}\mathbf{n = 2} & \\
\text { - Health Centre ' } J \text { ' (1 nursing officer in charge) } \\
\text { - Health Centre ' } \mathrm{K} \text { ' (1 nursing officer in charge) }\end{array}$ & $24 \%$ \\
\hline
\end{tabular}


Table 2: Demographic and Professional Characteristics of the Sample

\begin{tabular}{|c|c|c|c|}
\hline & $\begin{array}{c}\text { Interviews } \\
n=13\end{array}$ & $\begin{array}{c}\text { Focus Groups } \\
n=12\end{array}$ & $\begin{array}{l}\text { Total } \\
n=25\end{array}$ \\
\hline Age Range & $28-45$ years (mean $=38$ years) & $28-48$ years (mean $=36$ years) & \\
\hline Sex & $92 \%$ female & $75 \%$ female & $84 \%$ female \\
\hline Years of Work Experience & $2-21$ years (mean $=13$ years) & $6-22$ years (mean $=12$ years) & \\
\hline Registered Nurse $(\mathrm{RN})^{1}$ & $n=3$ & $n=0$ & $12 \%$ \\
\hline Enrolled Nurse (EN) & $\mathrm{n}=6$ & $\mathrm{n}=0$ & $24 \%$ \\
\hline Kenya Registered Community Health Nurse (KRCHN) & $\mathrm{n}=4$ & $\mathrm{n}=12$ & $64 \%$ \\
\hline Had received specialist training on HIV counselling & $\mathrm{n}=7$ & $n=6$ & $52 \%$ \\
\hline Had not received specialist training on HIV counselling & $\mathrm{n}=6$ & $\mathrm{n}=6$ & $48 \%$ \\
\hline
\end{tabular}

${ }^{1}$ Registered Nurses (RN) are mainly trained at diploma level (3 years of training) with a few having a BScN qualification (4 years of training). Enrolled Nurses (EN) are trained at a certificate level ( 2 years of training). The Kenya Registered Community Health Nurse (KRCHN) training (3.5 years) is done at the same level as the Registered Nurse but encompasses general nursing, community health nursing, midwifery and psychiatric nursing. KRCHNs, RNs and ENs all provide basic nursing care, however the RNs/KRCHNs are equipped with additional leadership and managerial skills which means that they often hold more senior leadership roles. However, this distinction is usually subject to availability of staff, for example, if a health centre in a rural area does not have a KRCHN nurse then the senior most EN will be the 'in charge'. 